\title{
System Reliability Analysis of Half-through Concrete-filled Steel Tubular Arch Bridge Based on Optimization Technique
}

\author{
LV Jing ${ }^{1, a^{*}}$ \\ ${ }^{1}$ Inner Mongolia Communications Planning and Design Institute Co., Ltd, Huhhot, \\ Inner Mongolia, China \\ a1498921958@qq.com
}

Keywords: Half-through concrete filled steel tubular arch bridge, Reliability, Reliability index, Structural system reliability, Optimization technique.

\begin{abstract}
The object of this paper analyzes the reliability of half-through concrete-filled steel tubular arch bridges. Load and resistance parameters are treated as random variables. The statistical parameters are based on the available literature, test data and survey results. Reliability indices of main components of the bridge structure are calculated by iterations using the first-order second-moment method. The half-through concrete-filled steel tubular arch bridge is the typical series system and the reliability index of the system is calculated by the optimization technique. The study shows that the optimization technique has a good application to example bridge which meet the requirement of ductile index.
\end{abstract}

\section{Introduction}

In early 1937, concrete-filled steel tubes were used extensively to make arch bridges in the former USSR. The arch bridge with a span of $101 \mathrm{~m}$ across the Neva River is one example of such a bridge. The first CFST arch bridge in China was completed in 1990. It is the Wanchang Bridge with a main span of $110 \mathrm{~m}$. Subsequently, more than two hundred CFST arch bridges have been built or are under construction in China. The half-through arch bridge is the most popular type of CFST arch bridge in China. Half-through arch bridges are constructed with the deck at some intermediate elevation between the springing and the crown. Yajisha Bridge $(360 \mathrm{~m})$ in Guangdong Province, Maochaojie Bridge $(368 \mathrm{~m})$ in Hunan Province, and Wuxia Yangtse River Bridge $(460 \mathrm{~m})$ in Chongqin are examples of half-through arch bridges [1]. On the basis of the cross-section, CFST arch ribs may be divided into single-tube-type ones, dumbbell-type ones, and space trusses with three to six tubes, etc. The rib diameter ranges from 450 to $2000 \mathrm{~mm}$, and the height varies from 1200 to $9000 \mathrm{~mm}$. Similarly, the thickness of the steel tubes ranges from 8 to $20 \mathrm{~mm}$. In general, the span of this kind of arch bridge ranges from 80 to $460 \mathrm{~m}$ - similar to those of steel arch bridges, but larger than those of concrete arch bridges. The deterministic analysis of stone and steel arch bridges have been studied in detail in the literature [2-7], but studies of CFST arch bridges have rarely been reported. This study focuses on analyzing the reliability of half-through concrete filled steel tubular arch bridge during the service stage.

\section{Bridge description}

The Jiantiao Bridge is a concrete-filled steel tubular half-through arch bridge. It is located at Sanmen City and the span of the bridge is $245 \mathrm{~m}$. The elevation of the bridge is shown in Fig. 1. The superstructure of the bridge consists of a vertical load bearing system, a lateral bracing configuration, and a floor system. The cross-section of the two main arch ribs comprises four concrete-filled tubes, with the dimensions of $800 \times 14 \mathrm{~mm}$. The depth of the main arch rib is $4400 \mathrm{~mm}$. There are 120 main suspenders, steel wire ropes, that are vertically attached on the main arch rib and the floor system is suspended through these. Each of these ropes consists of 61 smaller bars each with a diameter of $5.5 \mathrm{~mm}$. The floor system consists of a $250 \mathrm{~mm}$ thick concrete slab supported directly by cross-girders 
at a spacing of $5.9 \mathrm{~m}$. The cross-girder, the length of which is $23.5 \mathrm{~m}$, is the typical box cross-section. The main arch ribs are fixed at two abutments. Expansion bearings are constructed at the joints of the bridge and the road at the two ends of the bridge deck.

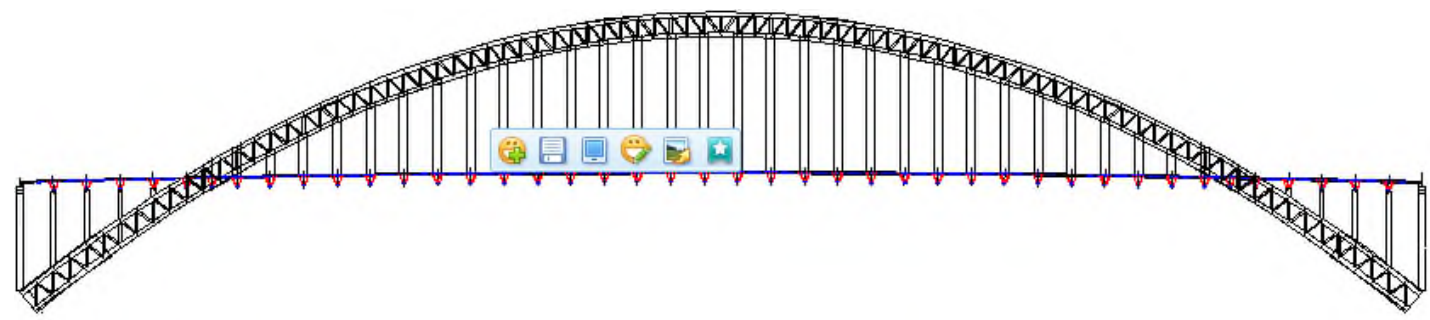

Fig. 1 The elevation of the bridge.

\section{Finite Element Modeling}

A three-dimensional linear FE model of the Jiantiao Bridge was developed in MIDAS/CIVIL. Fig. 2 shows the full 3-D view of the FE model of the arch bridge.

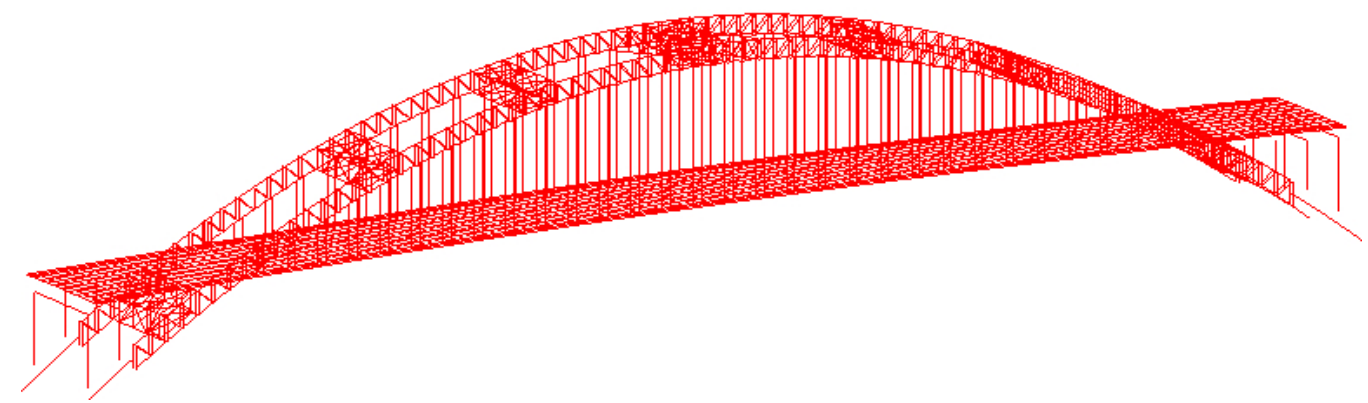

Fig. 2 The 3-D FE model of the bridge.

\section{Reliability Analysis}

Load Model. The load statistics for the example bridge are shown in Table $1[8,9]$.

Table 1. Load Statistics for the example bridge.

\begin{tabular}{cccc}
\hline Load & Distribution & Bias factor & Coefficients of variation \\
\hline Self weight & Normal & 1.0148 & 0.0131 \\
Pre-stress & Normal & 1 & 0.04 \\
Live load & Extreme I & 0.6861 & 0.1569 \\
\hline
\end{tabular}

\section{Resistance Model.}

The resistance model of suspenders. The resistance model of suspenders of the bridge is calculated using.

$$
R=[\sigma] n \frac{\pi}{4} d^{2} .
$$

where, $\sigma$ is the standard value of tensile strength in each bar, $n$ is the number of bar in each suspender, $d$ is the diameter of each bar.

The statistics of the resistance model of suspenders for the example bridge are shown in Table 2 [10].

Table 2. The statistics of the resistance model of suspenders for the example bridge.

\begin{tabular}{ccccc}
\hline Random variable & Distribution & nominal value & Bias factor & Coefficient of variation \\
\hline$\sigma$ & Normal & $1570[\mathrm{MPa}]$ & 1 & 0.05 \\
$d$ & Normal & $5[\mathrm{~mm}]$ & 1 & 0.05 \\
\hline
\end{tabular}


The resistance model of arch ribs. The resistance model of arch ribs of the bridge is calculated using [11].

$$
N_{\mathrm{u}}^{*}=\varphi_{l}^{*} \varphi_{e}^{*} N_{o}^{*} .
$$

where, $N_{\mathrm{u}}^{*}$ is the design value of carrying capacity, $\varphi_{l}^{*}$ is reduction coefficient of carrying capacity from slenderness ratio, $\varphi_{e}^{*}$ is reduction coefficient of carrying capacity from eccentricity ratio, and $N_{o}^{*}$ is the design value of carrying capacity of each axial compression short column.

$$
N_{o}^{*}=\sum_{1}^{i} N_{o i}
$$

where, $N_{o i}$ is the design value of carrying capacity of axial compression.

$$
N_{o i}=f_{c i} A_{c i}\left(1+\sqrt{\theta_{i}}+\theta_{i}\right) .
$$

where, $f_{c i}$ is concrete design value of compressive strength, $A_{c i}$ is cross-section area of concrete in steel tube, and $\theta_{i}$ is the confining index of concrete-filled steel tube.

$$
\theta_{i}=\frac{f_{a i} A_{a i}}{f_{c i} A_{c i}}
$$

where, $f_{a i}$ is the design value of compressive strength of steel tube, and $A_{a i}$ is the cross-section area.

From Eq. (2) to (5), Xu Fuyou [11] gives the resistance model of arch ribs,

$$
R=X_{1} \mu_{1}\left(X_{2} \mu_{2}+X_{3} \mu_{3}\right) \text {. }
$$

where, $X_{1}$ and $\mu_{1}$ are variables and mean value of which reduction coefficient of carrying capacity is derived from influence of slenderness ratio and eccentricity ration respectively, $X_{2}$ and $\mu_{2}$ are variables and mean value of steel resistance respectively, and $X_{3}$ and $\mu_{3}$ are variables and mean value of which resistance uncertainty from concrete restrained by steel tubular is considered.

The statistics of the resistance model of arch ribs for the example bridge are shown in Table 3 [11].

Table 3. The statistics of the resistance model of arch ribs for the example bridge.

\begin{tabular}{cccc}
\hline Random variable & Distribution & Bias factor & Coefficient of variation \\
\hline$X_{1}$ & Normal & 1.05 & 0.084 \\
$X_{2}$ & Log-normal & 1.3 & 0.13 \\
$X_{3}$ & Log-normal & 1.1 & 0.088 \\
\hline
\end{tabular}

The resistance model of cross-girders. The cross-girders are the prestressed concrete structure, therefore, the resistance model is log-normally distributed [12]. The bias factor is 1.121, and the coefficient of variation is 0.055 [13].

The resistance model of bracing members. The bracing members are the reinforced concrete structure, therefore, the resistance model is also log-normally distributed [12]. The bias factor is 1.4326 , and the coefficient of variation is $0.1517[13]$.

Limit State Function. Load and resistance are treated as random variables. The statistical models are based on the available literature. Ultimate limit state function in this study with the following limit state function,

$g=R-Q$.

where, $R$ is the resistance or load-carrying capacity, and $Q$ is the total load effect.

The total load is a sum of several components, $Q=D+L$, where $\mathrm{D}$ is the dead load effect, and $\mathrm{L}$ is the live load effect including impact. 


\section{Reliability Analysis.}

Reliability of the component. In this section, the reliability analysis of main components in the example bridge is performed with the first-order second-moment method [8]. Reliability analysis is performed for half-through concrete-filled steel tubular arch bridge designed according to the considered code. The reliability index, $\beta$, is defined as a function of probability of failure, $P_{F}$,

$$
\beta=-\Phi^{-1}\left(P_{F}\right) \text {. }
$$

where, $\Phi^{-1}$ is inverse standard normal distribution function.

Reliability index of the system. After calculating the reliability indices of main components of the example bridge, the reliability index of the system of the example bridge using the optimization technique [14] because the example bridge is the series system.

For a series system, the faiure region is the union of the failure regions of each limit state function. The equivalent limit state function of the series system can ba defined as

$$
G_{\text {series }}=\min \left(G_{1}, G_{2}, \ldots, G_{m}\right) .
$$

After calculating the correlation coefficients of suspenders, arch ribs and bracing members, the results indicate that they all have the high correlation. Therefore, the representative elements are 1-3\# of cross-girders, NO.60 element of suspenders, mid-span element of arch ribs and NO.1 element of bracing members, the reliability indices of which are 4.9982, 6.8079, 4.8545 and 5.9856 respectively.

The reliability index of series structure system based on optimization technique is

$$
\beta=4.8545 \text {. }
$$

The reliability index of equivalent series structure system based on PNET method is

$$
\begin{aligned}
P_{f} & =1-[1-\Phi(-4.9928)][1-\Phi(-6.8079)][1-\Phi(-4.8545)][1-\Phi(-5.9856)] \\
& =1-0.999999098=0.000000902 \\
\beta & =-\Phi^{-1}(0.000000902)=4.7742
\end{aligned}
$$

According to the result, the reliability index of half-through concrete-filled steel tubular arch bridge based on optimization technique is 4.8545 , which is larger $1.68 \%$ than PNET method of 4.7742, which indicates that the optimization technique has a good application to example bridge which meet the requirement of ductile index.

\section{Conclusions}

The reliability analysis is performed for half-through concrete-filled steel tubular arch bridge. The load and resistance parameters are treated as random variables, and the statistical parameters are taken from the available literature, test data and survey results. Subject to the limitations of the assumptions and parameters adopted in the study, the result indicates that the optimization technique has a good application to the example bridge which meets the requirement of ductile index.

\section{References}

[1] D. J. Ding. Development of Concrete-filled Tubular Arch Bridges, China. Struct. Eng. Int. (SEI), IABSE, 11 (2001) 265.

[2] B. C. Chen. Nonlinear Characteristics and Ultimate Load-carrying Capacity of Concrete-filled Tubular arch. A Thesis Submitted to Kyushu University, in Accordance with the Requirements for the Degree of Doctor of Engineering, Department of Civil and Structural Engineering, Japan (2003).

[3] P. Clemente. Introduction to Dynamics of Stone Arches. Earthq. Eng. Struct. Dyn. 27 (1998) 513. 
[4] C. W. Roeder, G. Macrae, P. Crocker et al. Dynamic Response and Fatigue of Steel Tied-arch Bridge. J. Bridge Eng. ASCE, 5 (2000) 14.

[5] T. Nonaka, A. Ali. Dynamic Response of Half-through Steel Arch Bridge Using Fiber Model. J. Bridge Eng. ASCE, 6 (2001) 482.

[6] R. Calcada, A. Cunha, R. Delgado. Dynamic Analysis of Metallic Arch Railway Bridge. J. Bridge Eng. ASCE, 7 (2002) 214.

[7] W. X. Ren, T. Zhao, I. E. Harik. Experimental and Analytical Modal Analysis of a Steel Arch Bridge. J. Struct. Eng. ASCE, 130 (2004) 1.

[8] Unified Standard for Reliability Design of Highway Engineering Structures(GB/T 50283-1999). Beijing: China Planning Press. (1999).

[9] K. W. Chaw. Reliability and Performance-based Design by Artificial Neural Network. Adv. Eng. Software. 38 (2007) 145.

[10]Z. W. Yu, S. S. He. Reliability Analysis of Ultimate Bearing Capacity of Concrete-filled Tubular Steel Stub Columns. Eng. Mech. 23 (2006) 139.

[11]F. Y. Xu, J. R. Zhang, H. X. Hao. Reliability Analysis of Stability of Arch Rib of Concrete-filled Steel Tubular Arch Bridge. J. Changsha Jiaotong University. 20 (2004) 6.

[12]A. S. Nowak. Calibration of LRFD Bridge Code. ASCE J. Struct. Eng. 121 (1995) 1245.

[13] Y. H. Li, W. G. Bao, X. W. Guo. Structure Reliability and Probabilistic Limit State Design of High-way Bridge. China Communications Press. (1997).

[14]C. Li, J. Meyer. Reliability evaluation of series systems with optimization technique. Chinese J. Comput. Mech. 21 (2004) 665.

[15]Q. Gao, S. C. Wu. Reliability Theory and Application in Civil Engineering. China Building Industry Press. (2007). 